\title{
Novas tecnologias, novas competências ${ }^{1}$
}

\section{New Tecnologies, new skills}

\author{
Geneviève Jacquinot Delaunay*
}

\begin{abstract}
RESUMO
O texto aborda a relação dos jovens e adolescentes com tecnologias, nem "novas" nem "velhas", e sim instrumentos para informar e comunicar, divertir, auxiliar nos trabalhos escolares. Apesar de reconhecer a familiaridade dessa geração com o que há de mais avançado em termos de tecnologia, aponta a necessidade de se compreender a complexidade desse novo cenário de aprendizagem, que envolve o aprofundamento de conceitos como interatividade e interação, linguagem numérica, multimídia, internet e hipertexto. Na seqüência, faz uma análise do contato dos jovens com essa diversidade de meios, suas implicações no processo cognitivo e suas conseqüências comunicacionais. Finalmente, reconhece que a aprendizagem é hipercomplexa e que - apesar de todo avanço científico - a máquina, mesmo interativa, não pode proporcionar ao indivíduo o aprendizado que lhe proporciona a interação com outras pessoas.
\end{abstract}

\begin{abstract}
The paper discusses how young people relate to technology, not seen as new or old, but as an instrument to communicate and keep informed, amuse and to help in school projects. Although it is clear that the new generations are much more familiarized with new technology, the focus is on the need to understand the complexity of the new scenario, which requires a deeper understanding of the concepts of interactivity, multimedia, internet and hypertext. It is discussed how young people enter in contact with this diversity of instruments. It is stressed, however, that no matter how complex the computer can be, nothing can replace the role of interacting with other people in the learning process.
\end{abstract}

${ }^{1} \mathrm{O}$ texto foi traduzido do francês por Rosa Maria Dallacosta, professora do Departamento de Comunicação e do Programa de Pós-Graduação em Educação da UFPR.

E-mail: rmcdcosta@ufpr.com.br.

* Professora emérita em Ciências da Educação, especialista em Mídia, Educação e Formação; ex- vice-presidente da Universidade Paris VIII, titular da Cátedra da Unesco de Formação a Distância e chefe de redação da Revista MédiaMorphoses, editada pelo Instituto Nacional do Audiovisual, ed: A. Colin. E-mail:gjacq@noos.fr. 
Para jovens que, desde que nascem, já conhecem a televisão, os vídeogames, os computadores, a Internet e os telefones celulares, não existem as "novas" e as "velhas" tecnologias: existem instrumentos para informar e comunicar, jogar ou ajudar nos trabalhos escolares.

Essa é uma distinção de adultos - pais, avós, educadores - para os quais, a cada surgimento de nova tecnologia, se faz necessário adquirir novos conhecimentos e novas formas de usos sociais. Eles, os jovens, ao contrário, aprendem rapidamente a utilizar cada nova tecnologia que faz parte do seu mundo e de suas relações sociais. É isso o que mostrou uma grande enquete européia realizada em dez países, além de Israel, na qual os trabalhos foram publicados em francês e em inglês ${ }^{2}$, que testemunha a influência das evoluções midiáticas sobre a maneira como as novas gerações conduzem suas relações familiares, sociais e escolares.

Esta enquete demonstra que apenas os livros - "velhos, com suas imagens em preto e branco", diz uma estudante de 11 anos - diferem de suas práticas habituais, levando em conta seu acesso seqüencial, como abordaremos a seguir.

Mas, se esses instrumentos lhes são assim familiares, isso não significa que esses jovens compreendam sua complexidade, nem que os utilizam adequadamente ou aproveitando todas as suas possibilidades. Além disso, as crianças não são iguais nem têm o mesmo acesso a esses diversos meios e aos serviços que eles podem oferecer. Na França, como em toda a Europa, e mais ainda nas diferentes partes do mundo, existem grandes disparidades tanto de equipamentos como de consumo e acesso aos meios, e é justamente por isso que a escola continua sendo um lugar privilegiado - ainda que imperfeito - para atenuar as desigualdades e para desenvolver não apenas uma prática instrumental, mas, sobretudo, um uso racional e uma cultura crítica dos meios e das redes que constituem o contexto do século XXI.

Para fazê-lo, os educadores têm necessidade de saber o que há realmente de "novo" nessas "últimas novidades" tecnológicas e de praticá-las, dia a dia, para aproveitá-las em sala de aula, ao serviço das novas modalidades de aprendizagem, e evitar - como acontece com freqüência - de tentar fazer o "novo" com o "velho"!

2 "L'enquête comparative européenne", in revue Réseaux, Paris, Hermès, vol.17, n. 92-93, pp 15-172, 1999; Sonia Livingston, Children and their changing meida environnement, Erlbaun, Londres, New Jersey, 2001. 


\section{A verdadeira novidade das NTIC}

\section{O computador e a linguagem numérica}

Sem entrar em detalhes técnicos, é necessário lembrar que foi através dos computadores que chegaram as "verdadeiras" novidades que nos fizeram passar progressivamente da era da reprodução técnica (foto-cinema-fonógrafo-vitrola) àquela que chamamos de era da "intertextualidade eletrônica".

A revolução eletrônica começou com o som e se desenvolveu com a banda magnética, depois atingiu a tecnologia da imagem com o vídeo e a televisão, mas é o computador e sua linguagem numérica que transformaram todo o setor de produção audiovisual. Lembramos:

- que chamamos numérico ou digital (de digit = chiffre em inglês) a linguagem informatizada ou o sinal, constituído de impulsos elétricos, e transmitidos sob a forma de elementos binários, 0 ou 1 (e não com 10 algarismos, como se considera no sistema de numeração decimal; nem com um sistema analógico que representa as variações de modo contínuo e não descontínuo, como é o caso do sinal de vídeo);

- que o computador com sua linguagem numérica pode criar, por um só cálculo, imagens (que chamamos justamente de imagens de síntese), mas que ele pode também recodificar todos os velhos textos como todas as velhas imagens e os velhos sons segundo o processo chamado de numerização;

- que o computador com sua linguagem numérica pode ainda misturar imagens, textos e sons de todas as origens e torná-los acessíveis, visíveis e auditíveis sobre uma mesma tela final: é essa intertextualidade eletrônica, o procedimento eletrônico que nos permite passar de um tipo de mensagem à multimídia.

Sendo o resultado de cálculos lógicos indefinidamente repetíveis e modificáveis, as imagens de síntese ou numeralizadas vão permitir a formação de modelizações da realidade, que por sua vez permite a simulação ou "manipulação de imagens fictícias", simulação de objetos, de imagens e mesmo simulações de papéis, como é o caso, no domínio lúdico dos vídeogames. Assim, podem ser criados, por simulação e acessíveis via interfaces mais ou menos sofisticadas, os 
diálogos, mas também os mundos ditos "virtuais", que existem apenas através do artefato da máquina: é esse o famoso diálogo homem-máquina.

Em conseqüência, as principais características dessas NTIC, que são tão diferentes das mídias sonoras e audiovisuais anteriores (com a condição, naturalmente, de se ter acesso ao hardware correspondente) são: a velocidade e a potência do registro, do arquivo e da restituição das informações textuais, visuais ou sonoras; o acesso, a mistura e a manipulação direta (em tempo real), por combinação, distorção, alteração de dados arquivados na memória (do computador): todo mundo conhece o exemplo do célebre quadro da Gioconda, refeito à imagem de cada internauta!

- a transportabilidade dos dados numéricos ou analógicos numeralizados, por diferentes canais de difusão (cabo, satélite, rede hertziana, fibra ótica...) e a conexão entre todas as redes; e a criação de "mundos virtuais" ou de "realidades artificiais" obtidas por modelização das formas do mundo real ou imaginário, e combináveis com os personagens e cenários reais como no caso dos imaginários ditos "híbridos", tudo isso tornado acessível, para o utilizador, via interfaces mecanizadas, suportes de interatividade.

\section{Interatividade e Interação}

O que é falar de interatividade? É propriamente falar do diálogo com um programa de informatização que governa o acesso a diversos dados. Desenvolvido originalmente no universo da informática - e, portanto, eminentemente técnico - , a noção de interatividade tem rapidamente escapado do mundo dos engenheiros para emigrar para diferentes esferas das atividades sociais ligadas às tecnologias, notadamente no domínio da imagem e dos meios (mídias).

Existem diferentes graus e diferentes tipos de interatividade, mas existem também funções diferentes de interatividade, o que é particularmente importante na pedagogia onde há freqüentemente a tendência de fazer da interatividade uma panacéia da pedagogia ativa e de confundir a interatividade mecânica, possibilitada pela máquina e seu programa, com a interação significante, aquela que dá sentido à ação humana que ela possibilita.

Se a interatividade é um conceito de origem técnica, relativamente novo, o da interação, ao contrário, é antigo e qualifica um processo de ação recíproca: em psicolingüística, são as trocas dialógicas entre duas ou mais pessoas; em psicologia social, a positividade das trocas em um grupo; em psicopedagogia, a influência recíproca e produtiva das trocas entre os alunos ou entre os alunos e o professor. 
É, portanto, necessário desconfiar um pouco da rápida transferência das capacidades interativas da máquina sobre as possibilidades de interações humanas, ou seja, intencionais. Se é verdade que, graças ao computador e à sua modalidade interativa, o espectador se torna "interativo" ou melhor "espectAtor", e que pode, por suas ações, influenciar o desenvolvimento do programa e o percorrer livremente, ainda é preciso saber (para aquele que concebe o programa) e que ele saiba (para aquele que o utiliza) o porquê: é necessário que seu gesto tenha sentido, tanto mais quando o objetivo perseguido é um objetivo de aprendizagem. Se, em um jogo didático, o resultado de um cálculo provoca a subida de bolas, não é suficiente que o aluno diga "é necessário fazer as bolas subirem".

Ou seja, não se pode confundir a interatividade própria da máquina com a interação mais ou menos significante que ela permite, de acordo com a maneira como foi concebido o programa e que dá forma à intenção que aquele que o concebeu tem da intenção de fazer que terá o aluno: "utilizar um programa didático é indiretamente engajar um diálogo entre os programadores/autores desse programa, procurar compreender suas intenções, objetivos e usos esperados. ${ }^{4}$

O multimídia não é, a priori, superior a nenhum dos outros meios para aprendizagem, da mesma forma que a internet não resolve todos os problemas de acesso à informação e aos saberes.

\section{Multimídia e Internet}

Essas reflexões sobre as características das tecnologias numéricas nos permitem melhor compreender o que são exatamente o multimídia e a internet. No multimídia, por exemplo, é necessário distinguir, se queremos utilizá-lo com fins educativos, que ele pode ser:

- enquanto suporte, um unimídia, pois nós podemos com uma mesma tela e com uma única máquina, o computador, ler, ver e entender mensagens para as quais anteriormente precisaríamos de aparelhos diferentes (gravador, projetor de slides ou de filmes...). E mais, pela primeira vez, também, com o multimídia e a internet, o instrumento de produção é o mesmo que o de difusão, o que não é o caso nem para o cinema, nem para a televisão, ou gravação de som e fotografia;

${ }^{3}$ A expressão é de Jean Louis Weisberg, Présences à distance, Déplacement virtuel et réseaux numériques, pourquoi nous ne croyons plus à la télévision, Paris: l'Harmattan/Communication, 1999.

${ }^{4}$ Michele Grossen et Luc Olivier Pochon, "Learning mediated by computers: to what extend is it situated?" Workshop on learning in Human and machines, European Science Foundation, Aix en Provence, 1995, in Perriault, J.,op.cit. 
- enquanto dispositivo técnico sensorial, um multimídia propriamente dito no sentido que ele mobiliza sentidos diferentes para a percepção das mensagens, a vista e o ouvido - mas também o odor, o gosto e o toque de certas simulações interativas;

- enquanto modalidades lingüísticas, um multimodal no qual a multimídia mistura linguagens diferentes tendo cada uma seu modo de funcionamento, linguagem oral, escrita, gestual, imagem desenhada, cinematográfica, videográfica, barulhos, músicas;

- enquanto estruturação, um hiperdocumento, uma organização não linear, ao contrário do livro, do filme ou da emissão televisiva clássica, mas reticular, como a chamam os que dizem que ela permite uma "navegação" através de caminhos diferentes: sem esquecer que o "espectAtor", assim autônomo que seja, não poderá jamais parar aqui onde o programador/autor terá decidido jogar a tinta;

- enquanto modo de difusão, o multimídia pode ser "integrado" em um CDrom, um DVDrom ou em um banco de dados, ou "repartido" quando ele é acessível pela rede internet: o que permite, nesse caso, a utilização coletiva, quer se trate dos jogos em rede ou do trabalho corporativo.

\section{As conseqüências cognitivas}

Se insistimos, na primeira parte deste capítulo, sobre as especificidades do numérico e, portanto das NTIC, é para mostrar que, contrariamente ao que se diz com freqüência, esses novos meios não são nem canais/tubos, nem instrumentos, mas sim "tecnologias intelectuais" as quais geram e nas quais são geradas condições de funcionamento de processos cognitivos: são máquinas que não trabalham mais a matéria bruta ou a energia, mas as informações e os conhecimentos e seus processos de apropriação. Elas vêm, assim, diretamente concorrer com a educação e os educadores no terreno tradicional do saber, justamente, a formação de saberes e a formação de espíritos - a famosa cabeça cheia e feita! 
Ora, é preciso desconfiar das facilidades e das possibilidades ofertadas pela máquina e seus usos testados ${ }^{5}$. A tradição do ensino (ao menos no Ocidente) repousa sobre a concepção do conhecimento concebido como acumulação, adição de saberes, "sobre a idéia de construir um edifício partindo do solo, partindo do zero e de começar a juntar peça por peça para construir". As tecnologias da informação e da comunicação nos obrigam a mudar essa perspectiva, a não mais limitar o olhar à aparência do mundo, e o conhecimento aos traços da informação: novos modos de ver e de pensar o real, e novas modalidades de comunicação aparecem e, em conseqüência, novos modos de acesso e de apropriação de saberes.

\section{O Hyperdocumento 6 e a leitura não-linear}

Pierre Lévy (1990) afirmava em seus primeiros livros que o "hipertexto ou o multimídia interativo se presta particularmente aos usos educativos, graças à sua dimensão reticular e não-linear, que favorece uma atitude exploratória, lúdica, diante do material a assimilar e que é, portanto, um instrumento bem adaptado a uma pedagogia ativa".

É no mínimo imprudente reforçar a crença tenaz nos meios pedagógicos que querem que a exploração de um hipertexto seja "de cara" mais fácil que a leitura de um texto - o que está bem longe de ser provado.

As raras pesquisas empíricas existentes colocam em evidência, ao contrário, entre outros?:

- a "sobrecarga cognitiva" que representa freqüentemente a ajuda à navegação: a energia e a atenção do aluno é freqüentemente dispersada em relação ao que é possível aprender em função de uma única atividade de navegação;

- a diferença entre os indivíduos faz com que os alunos não tenham a mesma autonomia diante de um dispositivo interativo;

- as diferenças entre os tipos de tarefas: parece que os sistemas de hipertexto são mais convenientes aos processos de resolução de problemas do que à aquisição de conceitos, por exemplo;

5 Jacquinot, G., 1998, "Du cinema éducateur aux plaisirs interactifs:rives et derives cognitives" in Cinéma et dernières technologies, INA/De Boeck Université, Beau, F., Dubois, P., Leblanc, G., (ss dir de) pp 153-170.

${ }^{6}$ Termo geral que inclui o hipertexto (navegação sobre dados textuais) e as hipermídias (sobre textos, mas também imagens e sons).

${ }^{7}$ Ver especialmente, lês actes dês journées bi-annuelles Hypernmédias et apprentissages publiées par B de la Passardière et G L Baron., INRP/EPI/MASSI, 1994 a 2000. 
- a difícil pesquisa da "compatibilidade cognitiva" entre o utilizador (aluno) e o sistema: pois se o sistema gera "conhecimentos" sobre os documentos, estes devem também estar assim na cabeça dos alunos: conhecimentos relativos à organização dos textos (então metalingüísticos) e conhecimentos relativos à situação de leitura (estratégicos) (ROUET, J. F.,1997).

Em contrapartida, quando utilizado com pertinência, o computador e seus programas interativos fornecem novos suportes ao pensamento, favorecendo certos processos cognitivos e permitindo também desenvolver o novo. Em particular, sua capacidade de estocar e deixar traços de itinerários seguidos pelos utilizadores pode ser um bom instrumento de avaliação, ou ainda de autoavaliação: que obstáculos foram encontrados, como eles foram superados, por quais alunos? Sua capacidade de relacionar (associar) os documentos, os dados de origem diferente (no tempo e no espaço) se transforma em um instrumento a serviço da flexibilidade cognitiva e da aptidão da mudança. A navegação livre e a exploração dinâmica com vistas à resolução de um problema identificado abrem perspectivas interdisciplinares e tornam possíveis descobertas por caminhos ainda não traçados. A interatividade enfim, atenua a separação clássica entre a postura do autor e aquela do leitor, e o utilizador pode ser sucessivamente emissor e receptor, aquele que produz e aquele que reage.

Contrariamente, então, a uma idéia já difundida nos meios pedagógicos, os sistemas multimídias, portanto interativos, não são "por natureza" os sistemas de aprendizagem pois a liberdade não é a chave de aprendizagem para todos e em todas as situações. Não é evidente que "avançar sobre um domínio desconhecido apareça como uma estratégia principal de aprendizagem", e nem os recursos expressivos da escrita interativa necessitam de novos autores e de novos espectatores. Enfim, e, sobretudo, parece necessário elaborar um modelo cognitivo geral dos processos de leitura, de expressão e de compreensão adaptada aos sistemas eletrônicos.

\section{O multimidia e a imagem interativa}

Ao multimídia interativo e essas dificuldades próprias à estruturação não-linear, juntam-se outras dificuldades - que devem também dar lugar à aprendizagem para se tornarem possibilidades - a saber essa dimensão multimodal. A psicologia cognitiva há muito tempo valoriza a linguagem verbal em detrimento de outras modalidades de expressão e de comunicação, como a imagem ou o gesto. Ela reconhece agora que a imagem e a linguagem são dois grandes domínios da cognição, que o funcionamento cognitivo repousa sobre 
o tratamento de informações verbais e não-verbais (imagens, sons, gestos) em constante interação (teoria de duplo codificação ${ }^{8}$ ), de onde vem a noção de multimodalidade.

A articulação das imagens e dos sons (comentário oral, texto escrito na tela, barulhos e músicas variadas) já era possível com os audiovisuais clássicos, e isso não se pode esquecer, com o multimídia.

Retomemos brevemente $^{9}$ (JACQUINOT, 1988) as características do pensamento analógico (visto no sentido das imagens) em relação ao pensamento lógico (funcionamento da linguagem):

- menor estatuto metalingüístico da imagem que necessita, da parte daquele que exprime como daquele que lê, uma maior "bricolage semiogenética" (capacidade de dar sentido), pois a imagem não marca de maneira explícita as operações a serem efetuadas para produzir sentido, ela não é equivalente ao que chamamos os "conectores"da língua;

- menor disposição da imagem de se ligar, de se absorver em figuras "secundarizadas" (no sentido dos processos secundários de Freud): ela escapa mais facilmente aos esquemas lógicos e resta então mais próxima do inconsciente e de suas modalidades próprias do encantamento (por condensação e deslocamento como em um sonho); para desempenhar uma significação, ela está mais próxima do imaginário e do afeto, e menos do lado racional;

- disposição natural, pela combinação de materiais sonoros e visuais a fazer funcionar simultaneamente;

- $\quad$ papel da montagem (entre imagens), esse "agitador de meninges" que permite suscitar as operações de raciocínio, fonte de atividades mentais. A imagem "permite acessar de uma outra maneira a compreensão, de se escorregar diferentemente na memória e de se apegar, para fixar e entreter a imaginação"10 - e a escola, salvo exceções, pouco a explorou.

${ }^{8}$ Teoria segundo a qual as informações verbais e as informações icônicas seriam tratadas por dois hemisférios diferentes do cérebro.

9 "Pas sage como une image" (ditado francês que diz "não santo como uma imagem") ou de l'utilisation des images em pédagogie, in Bulletin de psychologie, Tome XLI, n. 386, 1998, pp 603-609.

${ }^{10}$ Baiblé, C. "La transmission du savoir" in Les genres télévisuels dans l'enseignement, 1996, pp 53-67, op.cit. 
Mas aqui, ainda, a interatividade introduz uma especificidade: a imagem (e mesmo o som que a acompanha algumas vezes) de "olhar" (e escutar), como era antigamente, se torna "ação" "; ou seja, ela necessita da parte do utilizador uma ação, um gesto (no mínimo, clicar) para prosseguir. É necessário não se enganar: no plano da interpretação, as coisas não mudaram, a saber, que no desenho, pintura, fotografia, cinema, televisão ou síntese, a imagem é sempre "construída" pelo leitor que lhe confere um sentido, ela exige sempre uma função simbólica. Mas no caso da imagem interativa, ou "ação", a essa função simbólica se acrescenta uma outra "gestual", que exige um ato: imagem que existe "para" e "pelo" gesto, quedeve agir para vê-la e ver as conseqüências de seu gesto.

As operações cognitivas solicitadas são tão numerosas que merecem uma olhada: capacidade de previsão (o que clicar?), de observação (o que acontecerá?); mas também de análise das conseqüências do seu gesto (incidências recorrentes de um clicar) e de imaginação para dar sentido à associação produzida que afinal se trata de uma narração. Tantas outras ações a tratar freqüentemente em paralelo necessitam de uma capacidade de memorização, de recuperação no espaço, de antecipação e finalmente de atitude de mudança.

\section{O processo de tratamento da informação no computador}

A pesquisa informatizada das informações sobre internet, e mais especificamente sobre todo sistema documentário que relaciona o usuário e o computador, apresenta dificuldades para os alunos que não conseguem "aprender a aprender" com essas tecnologias. Tais dificuldades são de duas ordens: aquelas ligadas às palavras, conteúdos e objetivos a alcançar, e aquelas ligadas às ações, métodos e processos, sem falar da motivação (o que não é específico nessa atividade), mas também a eventuais dificuldades motoras (capacidade para lidar com o mouse ou com o teclado, por exemplo), o que é mais raro.

Quando um aluno procura a informação em um sistema informatizado, ele tem um objetivo e, para alcançá-lo, ele deve fazer um certo número de operações. Ora, freqüentemente, ele tem apenas uma representação vaga do que é um sistema documental informatizado, ele não sabe sempre quais instrumentos escolher e como respeitar as ordens, ele pára freqüentemente diante da primeira dificuldade, ou quando não encontra a resposta esperada. Além disso, essa atividade está essencialmente ligada ao domínio da língua; se ele comete erros ortográficos ao conduzir sua pesquisa na máquina, ou se não possui um vocabulário rico e variado, não poderá interrogar o banco de dados em todas as

${ }^{11}$ L'image actée: scénarisations numériques, sous la direction de Pierre Barboza et Jean Louis Weisberg, l'Harmattan, Coll. Champs visuals, 2006. 
suas possibilidades, uma vez que todos os sistemas não são sempre "tolerantes ao erro". Mas existem ainda outras dificuldades maiores ligadas à desconfiança do uso do instrumento: o aluno clica sobre todos os ícones antes de chegar àquele que lhe convém; ele consulta todas as respostas obtidas à primeira busca; mesmo se existam centenas, ao invés de modificar sua busca para afiná-la e obrigar o sistema a selecionar as principais respostas - notadamente utilizando pequenas palavras de articulação como "e, menos, ou".

Em pouco tempo, todas essas operações se tornam mais rápidas, mais exaustivas e mais pertinentes à pesquisa documental - temos acesso a todos os recursos documentais, sem sair do lugar, sem manipular numerosos fichários, segundo critérios de acesso diferentes, etc. - mas não atendem os objetivos, se nós não "aprendemos a aprender", tanto para as operações físicas como para as operações intelectuais que elas implicam. Contrariamente ao que se diz com freqüência, esses novos meios multimídias e interativos não são nem nós, nem instrumentos mas sim "tecnologias intelectuais" que geram condições de funcionamento (também temporais) de processos cognitivos. Elas oferecem aos artistas como aos educadores e documentaristas e a todos aqueles que procuram ter acesso à informação, saberes ou obras, novas possibilidades, uma nova escrita na qual o domínio como a generalização ainda estão por vir: o "saber programar não aumenta a capacidade de criar um programa além de clicar uma máquina nem dá talento para se escrever uma poesia."

\section{Conseqüências comunicacionais}

Estão ligadas às conseqüências cognitivas e, para torná-las mais claras nós a abordaremos separadamente. Em efeito, para que esses novos comportamentos e competências sejam solicitados pelo utilizador ou o aluno, é necessário que o dispositivo seja conhecido de alguma maneira e que as modalidades de expressão próprias da escrita numérica sejam utilizadas: nós falamos assim da "mise em scène da interatividade". Qual idéia de cenarização? Sobre o que repousa a construção do programa de informática? Quais são os ícones que aparecem sobre na tela? A que eles remetem? Como dispor dos diversos recursos midiáticos, imagens, sons, textos? Quando e como permitir ao espectador intervir? Para que fazê-lo? Como gerenciar o que surge e criar sintaxes de navegação fáceis? Tudo isso necessita de novas competências e novos talentos. 


\section{Os recursos expressivos da interatividade}

É aqui que vamos poder relacionar a interatividade mecânica com a interação significante.

Existem os cenários de interação que, no caso dos dispositivos com intenção educativa, remetem aos aspectos pedagógicos ou relacionais entre o usuário e o conteúdo que o suporte deve permitir de facilitar: trata-se de um diálogo socrático, de um comentário de texto como se fazia na Idade Média, de cenários behavioristas do estilo estímulo/resposta ou ainda de ambientes de aprendizagem tais como os concebe a teoria construtivista? Os multimídias, numerosos, que simulam a visita de um museu, por exemplo, reduzem a aprendizagem ao acesso à informação e ao passeio!

Para o usuário, em efeito, não é pela interatividade mecânica que ele se torna um ator, ele retrocede sobre o programa. Mas o que permite ao espectador "desenvolver uma atividade sensorial afetiva e intelectual ao serviço da interpretação da mensagem" é a interação significante: a interatividade não substitui, ela pode favorecer, ao invés de inibir, mais ela não a substitui jamais.

A interatividade que podemos chamar "intencional" é que se coloca entre o usuário e o autor, através dos engajamentos feitos por este durante a concepção do programa: ela remete à idéia de que o autor tem a intenção de que o usuário aprendiz tenha a intenção de fazer a partir do material que lhe é proposto, através da máquina e de seu programa.

Desse ponto de vista, uma máquina pode ter um baixo grau de interatividade funcional, como o vídeo ou o gravador, e permitir uma boa interação cognitiva pelo lugar que deixa ao espectador, na elaboração do sentido, a emissão que lhe propõe. Inversamente, uma máquina com alto grau de interatividade funcional como o computador pode não permitir uma interação cognitiva se o programa não tiver sido concebido com uma real interatividade intencional.

\section{Os recursos expressivos da multimodalidade}

De fato, como já foi constatado inúmeras vezes, se os CD-ROM e os DVD-ROM são sonorizados, a internet o é bem menos: internet é uma "máquina textual", muito mais ainda que um meio de expressão multimodal, ao menos até o presente.

Existem razões técnicas - nós sabemos que a imagem necessita, para ser arquivada, de muito mais de memória sobre o disco rígido do computador do que o texto e mesmo o som. Mas há também razões estéticas, a escrita numérica interativa, como nova modalidade de expressão e de comunicação, está ainda em constituição. Mesmo quando eles testemunham a integração de elementos 
textuais, sonoros e visuais. Desse ponto de vista, não é desnecessário lembrar as especificidades de cada modalidade de expressão antes de pensar na sua articulação em dispositivos interativos, pois a interatividade e a imagem "ação" que ela produz, pelo gesto do usuário, recompõem as articulações entre as diversas modalidades de significação.

A imagem analógica se desloca e se explora no espaço, enquanto a linguagem se desloca e se escuta em uma dimensão temporal segundo um desenvolvimento seqüencial assim como a música. Quanto aos elementos sonoros - fora do comentário no qual as funções de "ancoragem" e de "mudança" em relação à imagem foram há muito tempo exploradas e estudadas -, eles são sempre mais difíceis de ser analisados, pela sua natureza imaterial. $\mathrm{O}$ especialista do estudo do som no cinema, Michel Chion (1999), faz observações fundamentais: "para a imagem, há o quadro, para o som não existe equivalente do quadro. Nós podemos acrescentar sons ao infinito sem encontrar limites e esses sons podem ter níveis diferentes de realidade (música, voz em off, voz sincrônica), os sons se desfazem em relação ao quadro visual e ao seu conteúdo, é então em relação à imagem que os sons se repartem, uma repartição suscetível de ser colocada em questão a todo momento, desde que nós mudemos o que vemos".

Mas a situação evolui ainda quando se integra a essas especificidades a dimensão interativa: a imagem e o som interativos, mesmo que a dimensão interativa sonora, até o presente, por diversas razões, ${ }^{12}$ tenha sido menos explorada que a dimensão icônica, apresenta-se o problema do lugar e das funções do gesto na relação imagem-som. Nós podemos agir sobre diferentes parâmetros do som (duração, intensidade, timbre, efeito sonoro, espacialização) manipulando um objeto gráfico ou textual, jamais diretamente sobre o som, que não é representado fisicamente na tela, e a proximidade das diferentes modalidades expressivas, via unimídia, reforça o efeito de proximidade: a tal ponto que nós podemos dizer que em um dispositivo interativo multimídia "nós não sabemos mais se nós vemos o som, escutamos a imagem ou se tocamos a música" (Dominique Besson). Uma nova semiologia do som como da imagem interativa está nascendo. ${ }^{13}$

${ }^{12}$ Razões técnicas (peso dos fichários, desinteresse dos sistemas de autor pelo som) de natureza (seqüencial, imaterial) ou de cultura dos autores (vindos da imagem e do texto), mas a situação está mudando, de um lado no plano técnico (evolução do material e de programas) e, de outro, no plano do interesse dos autores e pesquisadores (em destaque, um deles, Hervé ZENOUDA).

${ }^{13}$ Ver a contribuição e a elaboração dessa nova semiologia em Barboza e Weisberg op.cit. 


\section{As conseqüências pedagógicas}

Antes de estar prometida a todas as revoluções cognitivas e comunicacionais, cada mídia ou rede de mídia deve ser caracterizada ao menos pelas funções específicas que preenche - é o que tentamos fazer em relação às tarefas de aprendizagem, o que nos resta fazer agora. Não objetivamos aqui as aplicações pedagógicas concretas dessas "verdadeiras" novas tecnologias, o que necessitaria um conhecimento e uma explicitação dos contextos de intervenção. Queremos somente, para terminar, evocar algumas conseqüências pedagógicas globais inseridas nas características precedentemente colocadas.

Não há o menor interesse nessas tecnologias além de nos fazer pensar nas questões da aprendizagem. Elas nos levam a tomar consciência de que a inteligência não se limita à racionalidade calculadora da inteligência justamente chamada "artificial" e que a aprendizagem é um processo hipercomplexo. As diferentes experiências sobre os dispositivos interativos, a serviço da comunicação como da informação, colocam justamente em evidência um dos problemas fundamentais da utilização de interfaces inteligentes: a saber "a estrutura de programa do sistema informático é forçosamente lógico quando a estrutura cognitiva é freqüentemente pouco lógica junto ao usuário". Portanto, é necessário estabelecer uma comunicação entre os dois, e nós começamos a perceber as contradições que impõe essa famosa inteligência humana "a quatro mãos". Dito de outra forma, a máquina não funciona de forma intersubjetiva: um indivíduo não aprende jamais sozinho, mas na interação com outras pessoas. Compreender o ponto de vista de outras pessoas é um aspecto essencial da atividade de aprendizagem, que a máquina - mesmo interativa - não pode lhe oferecer. Essa constatação é particularmente importante quando nós intencionamos colocar esses recursos eletrônicos a serviço da aprendizagem: uma nova pedagogia está a ser criada e como sempre são necessários inventores (JACQUINOT, 1985).

Uma primeira precaução a ser tomada é a de saber fazer distinção sobre esse termo genérico de "novas tecnologias", nascido do numérico, entre as técnicas eletrônicas de consulta e de tratamento da informação e os instrumentos de comunicação.

Na primeira categoria nós podemos agrupar os programas didáticos, os $\mathrm{CD}$ ROM e DVD-ROM, os programas de apresentação visual de informação (Power Point, Word, Flash...), os robôs pedagógicos, as bases de dados documentários, a consulta de sites. Na segunda, os grupos de discussão, os fóruns (por escrito, em asynchrone) ou os chat, o monitoramento à distância, as diferentes formas de áudio e de vídeo conferência e os correios eletrônicos, assim graciosamente chamados de "courriel" pelos quebequenses. 
Outros critérios permitem distinguir aqueles que se utilizam individualmente ou coletivamente, em sincronia (em tempo real) ou em não-sincronia (tempos diferenciados). Segundo essas categorias, a função de instrumentação - entendida como uma função que tem um instrumento para a realização de uma ação determinada - não é a mesma e a escolha deve se fazer em função da situação pedagógica e dos objetivos que se persegue.

Desse ponto de vista, os hiperdocumentos são bem diferentes da internet e levam em consideração ou "instrumentalizam" diferentes funções, segundo a maneira como são concebidos, e segundo o que eles procuram mais ou menos guiar da demanda do aprendiz. Os hiperdocumentos têm fins de aprendizagem - quer sejam eles de simples intertextos ou de hipermídias (ROUET, 1997). Substituem a pesquisa manual de documentos em um ambiente físico complexo e de difícil acesso. Materializam relações de sentidos (semânticas) entre documentos individuais, relações que são freqüentemente implícitas mas que fazem parte de conhecimentos a serem adquiridos. Associam informações de diferentes tipos (textos literários, texto oficiais, definições, opiniões, de periódicos e de contextos diferentes...) e, portanto, favorecem tomadas e mudanças de perspectivas. Permitem, graças aos instrumentos de navegação, consultar as informações úteis para a tarefa evitando outras, inúteis, no momento da aprendizagem visada (e se a opção pedagógica tomada é a de guiar melhor o aprendiz).

Não é o caso da internet, em revanche, onde as informações estão lá livremente, sem terem sido previamente selecionadas em função das necessidades de aprendizagem do aluno que as consulta. Ele deve afinar sua pesquisa de informação, avaliar a qualidade da informação encontrada, controlar sua veracidade, inseri-la no conjunto de outras fontes que ele já possui, memorizar as principais etapas do seu percurso, não perder de vista o que procura, estruturar todas essas informações, estruturação que sozinha lhe permite a passagem da informação ao conhecimento. Se aparecer um problema, deve aprender a lidar com o inesperado, procurar uma solução, simular e comparar diversas soluções para alternativas, guardar as etapas do seu percursos de pesquisa e compará-las a outras.

Finalmente, instrumentos de informação e/ou de comunicação, uns e outros, implicam uma nova gestão do espaço e do tempo, uma nova relação com a presença e a ausência: as referências mudaram, os ritmos também. As diversas modalidades do nosso funcionamento cognitivo são diversamente valorizadas segundo as culturas, diversamente representadas segundo os indivíduos e diferentemente solicitadas segundo as máquinas e os recursos expressivos que privilegiam. O que podemos dizer com a simulação e a interatividade parece introduzir uma relação mais diretamente operatória, "sensorial 
motora", à experiência de aprender que ela permitia - ao menos por aqueles que não freqüentaram suficientemente cedo seu contexto social ou cultural - a cultura do livro e mesmo a cultura audiovisual: percebemos imediatamente as conseqüências de seu gesto.

Mas convém ainda especificar o sentido dado a esse gesto, ou distinguir as diferentes funções da interatividade. Com efeito, graças a essa modalidade expressiva, e mediando a disponibilidade das interfaces e programas correspondentes, nós podemos procurar individualizar um percurso exploratório e de aprendizagem; dar um acesso a uma ajuda, seja ela da ordem de explicação de uma palavra desconhecida sobre a qual nós clicamos e damos uma definição, ou da ordem de uma indicação técnica (como fazer?) ou histórica (que tenho feito até o presente?); nós podemos nos relacionar com outros e colaborar coletivamente com uma mesma tarefa; podemos intervir diretamente na imagem ou mensagem para modificá-la; podemos também, graças a interfaces específicas, ter acesso a mundos virtuais, a ver, a sentir, a tocar... estar presente à distância ${ }^{14}$ !

Na realidade, com essas novas mídias, o que está em questão, tanto no plano estético como no pedagógico, são as novas situações de percepção e de representação, que necessitam, de novas teorias de significação e de novas concepções de aprendizagem - em conseqüência, para os educadores, como para os alunos, novas competências. A escrita interativa oferece com efeito a possibilidade de contribuir para o enriquecimento do regime de comunicação pedagógica, pela exploração dos recursos próprios aos meios eletrônicos - interatividade, simulação e hipermediação. Em que condição? A mesma que aquela que fazia os conceptores e realizadores pela utilização do cinema e da televisão com fins educativos e pedagógicos: evitar reproduzir, com os novos meios de expressão, o modelo canônico da mediação pedagógica clássica, linear e verbal. Explorar os recursos específicos dessas modalidades enunciativas e discursivas para "fazer aprender de outra maneira".

${ }^{14}$ G., Jacquinot-Delaunay, G. "Au-delà du modèle canonique de la relation maître-élève: les TIC ou comment faire circuler les signes de la présence". In: Prtatiquer les TICE: former les enseignantes et les formateurs à de nouveaux usages”. De Boeck: Bruxwelles, 2002. 


\section{REFERÊNCIAS}

CHION, M. L'audio-vision. Paris: Nathan/Université, 1990.

JACQUINOT, G.; LEBLANC, G. (Dir.). Les genres télévisuels dans l'enseignement. Paris: Hachette/Education CNDP. Traduit en italien sour le titre Appunti per una lettura del cinema e della televisione. Naples: Editoriale Scientifica, 1999.

JACQUINOT, G.; MEUNIER, C. (Dir.). L'interactivité au service de l'aprentissage. Revue dês sciences de l'éducation, Québec, v. 25, n. 1, 1999.

JACQUINTO, G. L'école devant lês écrans, Col. Science de l'Education. Paris: Edition ESF, octobre 1985. 135 p. Traduction espagnole actualisée: La escuela frente a las pantilas. Buenos Aires: AIQUE, 1996. 195 p.

LÉVY, P. Lês techonogies de l'intelligence. Paris: La Découverte, 1990.

LINARD, M. Dês machines et dês hommes: apprendre avec lês nouvelles tecnologies. Paris: Anthropos, 1996.

PERRIAULT, J. Education et nouvelles technologies, théories et pratiques. Paris: Nathan/Université, 2002. coll. 128 (pages).

ROUET, J. F. Le lecteur face à hypertexte. In: CRINON, J.; GAUTELLIER, C. (Dir.). Apprendre avec le multimedia: où en est-on? Paris: CEMEA/Retz, 1997. p. 165-180.

WEISBERG, JL.; BARBOZA, P. (Dir.). L’image actée: scénarisations numériques, l'Harmattan, Coll Champs visuels, 2006.

Texto recebido em 12 abr. 2007 Texto aprovado em 27 set. 2007 